\title{
The Moderating Role of Context in Determining Unethical Managerial Behavior: A Case Survey
}

\author{
Christof Miska $^{1}$ Günter K. Stahl ${ }^{1} \cdot$ Matthias Fuchs $^{1}$
}

Received: 2 January 2016/ Accepted: 31 October 2016/Published online: 29 November 2016

(c) The Author(s) 2016. This article is published with open access at Springerlink.com

\begin{abstract}
We examine the moderating role of the situational and organizational contexts in determining unethical managerial behavior, applying the case-survey methodology. On the basis of a holistic, multiple-antecedent perspective, we hypothesize that two key constructs, moral intensity and situational strength, help explain contextual moderating effects on relationships between managers' individual characteristics and unethical behavior. Based on a quantitative analysis of 52 case studies describing occurrences of real-life unethical conduct, we find empirical support for the hypothesized contextual moderating effects of moral intensity and situational strength. By examining these complex contextual moderators, we aim to contribute to organizational ethics research as we shed light on the critical role that context may play in influencing unethical managerial behavior.
\end{abstract}

Keywords Case survey $\cdot$ Moral intensity $\cdot$ Multidetermined antecedents · Organizational ethics $\cdot$ Situational strength $\cdot$ Unethical managerial behavior

\section{Abbreviations \\ AVE Average variance extracted}

Christof Miska

christof.miska@wu.ac.at

Günter K. Stahl

guenter.stahl@wu.ac.at

Matthias Fuchs

mattifuchs@gmail.com

1 Department of Global Business and Trade, Institute for International Business, Vienna University of Economics and Business (WU Vienna), Building D1, Welthandelsplatz 1, 1020 Vienna, Austria
CMD Cognitive moral development

EWC Ethical work climate

ICC Intra-class correlation coefficient

MI Moral intensity

MP Moral philosophy

SEM Structural equation modeling

\section{Introduction}

Over recent decades, the extant body of organizational ethics research has identified numerous antecedents of unethical managerial behavior, including individual characteristics, situational and moral-issue aspects, and organizational factors. In explaining unethical managerial conduct, both theoretical and empirical research traditionally emphasize characteristics of individual managers (cf., O'Fallon and Butterfield 2005) and show a strong focus on trait theory, which assumes consistent patterns of individual behavior due to stable dispositional traits. In contrast, recent reviews and meta-analyses (Craft 2013; KishGephart et al. 2010; Lehnert et al. 2015; Moore and Gino 2015; Treviño et al. 2014) increasingly point to the importance of situational and organizational contexts in influencing unethical behavior in organizations. For example, Palmer (2013, p. 5) argues that managerial misconduct is "perpetrated by people who are for the most part upstanding (otherwise ethical, socially responsible, and law abiding), and is a function of a plethora of structures, processes, and mechanisms that are integral to the efficient and effective functioning of organizations". This is in accordance with work in social psychology (e.g., Mischel 1968 , 1973) that traditionally makes a strong case for the power and the situational strength of the context in which individuals act. Thus, unethical managerial behavior is not 
only a function of individual characteristics, but is influenced by the situational and organizational contexts in which managers operate.

However, while some early conceptual work in the organizational ethics literature (e.g., Jones 1991; Treviño 1986) has proposed how individual characteristics and contextual factors might combine and determine ethical and unethical behaviors, few empirical examinations of such moderating effects have been conducted. Lehnert et al. (2015) in their review observed a number of organizational ethics studies testing moderators. However, only a few of these related to contextual moderating effects, and those that did for the most part examined select contextual factors. The authors noted that a focus on interactive effects is required in order to truly understand the boundary conditions of ethical behaviors. Correspondingly, KishGephart et al. (2010) remarked that "there is a need for broader band research that investigates more complex configurations of individual, moral issue, and organizational environment variables" (p. 23). Thus, while the organizational ethics literature has identified numerous individual, situational and moral issue, as well as organizational antecedents of unethical managerial behavior, the gap in existing research relates to how individual characteristics and contextual factors may combine. This gap is important because the complex interactions between individual characteristics and contextual influences provide great potential to more clearly understand the boundary conditions of unethical managerial behavior.

We aim to address this gap by empirically examining the moderating role of the contexts in which managers act in order to explain unethical managerial behavior. Lehnert et al. (2015) noted that the high complexity of the business environment makes it challenging to isolate the influence of such contextual moderating influences, and Bartlett (2003) suggested methodological considerations to accomplish such interrelations. We therefore use the casesurvey methodology (Larsson 1993) to test for contextual moderating effects, as it allows the examination of realworld unethical managerial behavior in its full complexities.

We first review extant work on organizational ethics, summarizing the numerous antecedents of unethical behavior in the work context identified by previous research. We then draw on the concepts of moral intensity (Jones 1991) and situational strength (Mischel 1968, 1973) to hypothesize that situational and organizational contexts moderate the effects of managers' individual characteristics on unethical behavior. While the first is a well-established construct in the organizational ethics literaturewhere its moral-issue components have been frequently directly associated with unethical behavior as situational antecedents (Kish-Gephart et al. 2010)—-the latter is rather novel to the field and helps grasp the role of context beyond the immediate moral issue in question. Consequently, we aim to examine the moderating role of context by considering both the specific moral situation and the organizational ethical infrastructure, and thus adopt a holistic perspective on the context in which unethical managerial behavior occurs.

We test our hypotheses on a sample of 52 case studies describing occurrences of real-life unethical managerial behavior. In this way, we quantify the information gathered from case studies and analyze it statistically (Bullock and Tubbs 1987; Jauch et al. 1980; Larsson 1993) using structural equation modeling (Ringle et al. 2005) and regression analysis. We aim to contribute to organizational ethics research by shedding light on the critical role that context may play in influencing unethical managerial behavior.

\section{Literature Review}

Notably, in the organizational ethics literature several literature streams have emerged seeking to address the range of antecedents that might affect ethical and unethical behaviors in organizations. Sonenshein (2007) identifies three major streams: managers as philosophers, person-situation theories, and issue-contingent approaches. The first stream assumes that managers apply normative theories to resolve ethical dilemmas. An example is Hunt and Vitell's (1986, 1993, 2006) general theory of marketing ethics, which grants a central role to individuals' moral philosophies. The second stream is characterized by an interactionist perspective, as exemplified by Treviño's (1986) person-situation interactionist model, which combines individual and situational characteristics to predict ethical decision-making behavior in an organizational context. The third stream, as exemplified by Jones's (1991) influential theory of moral intensity, seeks to explain how the characteristics and dimensions of moral issues affect ethical decision-making. Other approaches place greater emphasis on antecedents of the proximal context. For example, Fritzsche's (1991) model of decision-making incorporates individual ethical values, with the assumption that they are mediated by organizational elements, such as the organizational climate or goals. This interaction of personal values and organizational influences should result in decisions that differ significantly from those based solely on personal values.

Despite these variations in conceptualizing and explaining ethical and unethical behaviors, a common theme in organizational ethics research is that these behaviors are determined by individual characteristics, aspects of the immediate situation or moral issue at hand, 
and organizational influences. Due to the multi-determined nature of unethical choice (Kish-Gephart et al. 2010), it is important to take into consideration these multiple-antecedent sets (Flannery and May 2000; Treviño and Weaver 2003). Therefore, in the following we draw upon this multiple-set logic and describe how extant research conceptualizes the three sets of antecedents, highlighting those that, based on empirical research, are commonly directly associated with unethical managerial behavior.

\section{Multiple-Antecedent Sets of Unethical Managerial Behavior}

\section{Individual Characteristics}

These are the most widely researched antecedents of unethical behavior. O'Fallon and Butterfield (2005), in their comprehensive review of the empirical ethical decision-making literature from 1996 to 2003, find that research in this area overwhelmingly addresses individual factors, as opposed to other antecedents: $70 \%$ of the variables focused on individual characteristics. A comparable trend was observed by Craft (2013), who reviewed more recent literature. A possible explanation for this over-emphasis likely stems from several influential theoretical frameworks in organizational ethics research, which focus mainly on individual characteristics, such as Rest's (1986) ethical decision-making framework and Kohlberg's (1969) stage model of cognitive moral development (CMD).

We identified three categories of individual characteristics commonly found to be directly associated with unethical behavior: personality constructs, philosophy or value orientations, and other individual characteristics. Our aim was not to create an exhaustive list of antecedents, but to identify factors most frequently linked to unethical behavior in each category.

First, the personality constructs category includes concepts such as Machiavellianism (Christie and Geis 1970; Gilbert 1971) and locus of control (Rotter 1966; Treviño 1986). Machiavellianism can be defined as a strategy of social conduct that implies manipulating others, often against their own interests, for personal gain (Wilson et al. 1996). Consequently, from a behavioral perspective Machiavellianism is usually associated "with amoral action, sharp dealing, hidden agendas, and unethical excess" (Nelson and Gilbertson 1991, p. 633). KishGephart et al. (2010), in their meta-analysis of sources of unethical work decisions, found clear support for a link between Machiavellianism and unethical behavior. Another commonly researched personality construct is locus of control, which represents a continuum that captures people's tendencies to believe that their actions are dependent on themselves (internals) or contingent on outside forces (externals). Treviño (1986) proposed that externals are more likely to engage in unethical behavior, as they are less likely to take personal responsibility for the consequences of their actions, a link that empirically finds support (Kish-Gephart et al. 2010).

Second, moral philosophies are rooted in normative philosophical theories and refer to people's preferences and justifications for normative orientations. Prior research tends to find a fairly consistent pattern of relationships between moral philosophies and unethical choices, especially positive linkages between teleological and relativistic orientations and negative links for deontological and idealist ones (O'Fallon and Butterfield 2005). Teleological approaches are aligned toward ends, which may justify unethical behavior, while deontological approaches emphasize duties independent of consequences, which might restrain individuals from engaging in unethical behavior. Correspondingly, relativism assumes that normative beliefs are dependent on contexts, while idealism implies universal ethical rules.

Third, the category of other individual factors refers to a number of antecedents associated with persons' attitudes, demographics, and backgrounds. Despite mixed findings about the effects of such variables on unethical behavior (Craft 2013; Lehnert et al. 2015; O'Fallon and Butterfield 2005), two antecedents are notable for their frequent association with unethical behavior: job satisfaction and whether or not a person has undergone ethics training. Kish-Gephart et al. (2010) in their meta-analysis find support for a negative relationship between job satisfaction and unethical behavior. This finding is consistent with equity theory (Adams 1965), which predicts that dissatisfied people will seek to rebalance perceived imbalances, in some cases through unethical behavior. In relation to ethics training, the theoretical link is not entirely clear (KishGephart et al. 2010) and empirical findings on its effects tend to be mixed (Laufer 1999; McCabe et al. 1996; Richards 1999; Stansbury and Barry 2007); yet more recent research (Warren et al. 2014) suggests that comprehensive ethics training can have negative effects on unethical behavior. Notably, and as remarked by Kish-Gephart et al. (2010), individuals with a higher educational background may have been exposed to more explicit training, which might also be more comprehensive. We therefore refer to the demographic, and thus individual, component of ethics training rather than its organizational aspect.

\section{Situational and Moral-Issue Characteristics}

An influential, well-recognized theory of the characteristics of moral issues and their impact on ethical and unethical behavior is Jones's (1991) theory of moral intensity, which postulates that each morally charged situation or moral issue at hand can be characterized by six dimensions: the 
magnitude of consequences of the act in question as the sum of its harms or benefits to those affected; social consensus as an agreement by peers that the act is evil or good; the probability of effect, as the likelihood that the act results in harm or good; temporal immediacy, as the span of time before harmful or beneficial consequences of the act occur; proximity, in the form of social, cultural, psychological, or physical closeness to the victim or beneficiary of the act; and concentration of effect, which is "the inverse function of the number of people affected by an act of given magnitude" (Jones 1991, p. 377). A large body of empirical research has investigated the moral-issue components and their linkages to unethical behavior, finding generally good support (Craft 2013; O'Fallon and Butterfield 2005) for negative relationships, although not all dimensions are equally strongly related to unethical decision-making.

\section{Organizational Characteristics}

In this set, we identify three categories of the organizational environment or organizational ethical infrastructure, which have often been associated with unethical managerial behavior: ethical work climate, ethical culture, and codes of conduct.

First, Victor and Cullen $(1987,1988)$ offer ethical climate theory as a subset of theories of organizational work climates, combining work on socio-cultural organization theories (Schneider 1983) with Kohlberg's (1969) CMD theory. Essentially, an ethical work climate captures employees' beliefs that "certain forms of ethical reasoning or behavior are expected standards or norms for decisionmaking within the firm" (Martin and Cullen 2006, p. 177). Victor and Cullen $(1987,1988)$ derive nine theoretically possible climate types, and further empirical work (e.g., Bulutlar and Öz 2009; Martin and Cullen 2006; Simha and Cullen 2012; Tsai and Huang 2008) finds five types as the most common: caring (concerns about the well-being of others), law and code (adherence to external regulations and codes), rules (adherence to organizational standards such as codes of conduct), instrumental (decision-making from an egoistic and self-centered perspective), and independence (deeply held personal moral beliefs). Prior research has linked the ethical work climate concept to unethical behavior (Bulutlar and Öz 2009; Wimbush et al. 1997), finding positive linkages of egoistic climate types and negative relationships of benevolent and principled climate types with unethical behavior (Kish-Gephart et al. 2010).

Second, Treviño et al. (1998) differentiate ethical climate from ethical culture as distinct, though strongly related, constructs. Ethical culture represents a subset of organizational culture, entailing the "multidimensional interplay among various "formal" and "informal" systems of behavioral control that are capable of promoting either ethical or unethical behavior" (Treviño et al. 1998, p. 451). Thus, the construct refers to ethical culture in a broad sense, but also more narrowly to specific reward and sanction systems that communicate behavioral expectations. Treviño and Youngblood (1990) build on social learning theory to argue that organizational sanctions influence outcome expectations and employees' ethical behavior. Similarly, and rooted in deterrence theory, Treviño (1992) proposes that sanctions can restrain people from engaging in misconduct if the punishment is strong enough to override the benefits of misbehavior. Reviews of the empirical ethical decision-making literature (e.g., Craft 2013; O'Fallon and Butterfield 2005) tend to confirm these relationships.

Third, codes of conduct can provide employees with guidelines for appropriate behavior. However, they vary in their "implementation strength" (McCabe et al. 1996, p. 464), and scholars tend to find mixed results regarding the effectiveness of such codes in discouraging unethical behavior (e.g., Brief et al. 1996; Cleek and Leonard 1998). In relation to unethical behavior, Kish-Gephart et al. (2010) distinguish between code existence and code enforcement, finding support for negative effects of the latter.

Table 1 provides an overview of the three sets of antecedents and their direct effects on unethical managerial behavior, as generally identified in extant literature (column: Effects as indicated by the literature). Next, we draw on the concepts of moral intensity (Jones 1991) and situational strength (Mischel 1968, 1973) to predict that these two key contextual factors moderate the effects of individual characteristics on managers' unethical behavior.

\section{Contextual Moderating Effects of Moral Intensity and Situational Strength}

While the extant body of organizational ethics research has identified numerous contextual antecedents of unethical managerial behavior (as described previously pertaining to situational and moral-issue characteristics as well as the organizational ethical infrastructure), only recently have scholars (e.g., Kish-Gephart et al. 2010; Lehnert et al. 2015) specifically pointed out the need to examine how individual characteristics and context interact and influence unethical managerial behavior. In order to conceptualize contextual moderating effects, we draw on Jones's (1991) moral-intensity theory to hypothesize situational and moral-issue moderating effects, and we apply Mischel's (1968, 1973) situational-strength construct to hypothesize organizational moderating effects on the relationship between managers' individual characteristics and unethical behavior. 
Table 1 Overview of study variables, effects on unethical managerial behavior, and inter-rater reliabilities

\begin{tabular}{|c|c|c|}
\hline Study variable & Effects as indicated by the literature & ICC \\
\hline \multicolumn{3}{|l|}{ Dependent variable } \\
\hline Unethical managerial behavior & & 0.87 \\
\hline \multicolumn{3}{|l|}{ Individual characteristics } \\
\hline Machiavellianism & + & 0.93 \\
\hline External locus of control & + & 0.77 \\
\hline \multicolumn{3}{|l|}{ Moral philosophies } \\
\hline MP-moral equity & - & 0.87 \\
\hline MP-relativism & + & 0.84 \\
\hline MP-contractualism & - & 0.95 \\
\hline MP-utilitarianism & + & 0.82 \\
\hline MP-egoism & + & 0.84 \\
\hline Job satisfaction & - & 0.91 \\
\hline Ethics training & - & 0.97 \\
\hline \multicolumn{3}{|l|}{ Situational and moral-issue characteristics } \\
\hline MI-magnitude of consequences & - & 0.83 \\
\hline MI-social consensus & - & 0.91 \\
\hline MI-probability of effect & - & 0.93 \\
\hline MI-temporal immediacy & - & 0.87 \\
\hline MI-proximity & - & 0.82 \\
\hline MI-concentration of effect & - & 0.91 \\
\hline \multicolumn{3}{|l|}{ Organizational characteristics } \\
\hline \multicolumn{3}{|l|}{ Ethical work climate } \\
\hline EWC-caring & - & 0.90 \\
\hline EWC-law and code & - & 0.92 \\
\hline EWC-rules & - & 0.91 \\
\hline EWC-instrumental & + & 0.94 \\
\hline Ethical culture & - & 0.85 \\
\hline Existence of rewards and sanctions & - & 0.85 \\
\hline Existence of code of ethics & - & 0.92 \\
\hline Enforcement of code of ethics & - & 0.92 \\
\hline
\end{tabular}

\section{Moral Intensity}

Jones (1991), as described previously, defines the collective of the six situational characteristics related to the moral issue in question as moral intensity, which rises and declines rather monotonically according to increase or decrease in any one or more of the six dimensions. Following an issue-contingent logic and drawing from social psychology, he concludes that people may deal variably with ethical decision-making depending on the moral intensity of such situations. Consistent with this logic, May and Pauli (2002) propose that conceptualizations of the potential moderating role of moral intensity may be promising for further theory development concerning the linkages between contextual influences and ethical decision-making. Flannery and May (2000) found first empirical support for such moderating effects in the setting of managers' environmental ethical decision intentions. More recently, Lehnert et al. (2015) noted that moral intensity is an important component in any discussion of ethical decision-making, and suggested examining its moderating as well as other types of effects.

Moral intensity can serve as an indicator for ethical behavior, with higher moral intensity tending to indicate the salience of the moral issue at hand (e.g., Valentine and Bateman 2011; Leitsch 2004). Thus, the higher the moral intensity of an ethically charged situation, the more likely individuals are attentive to the issue in question and adjust their behavior accordingly. Correspondingly, we propose that moral intensity can reduce the effects of individual characteristics that predispose managers to engage in unethical behavior (e.g., Machiavellianism, external locus of 
control, etc.) and augments the effects of personal characteristics that might predispose managers to refrain from unethical behavior (e.g., deontological and idealistic moral philosophies). For example, social consensus as one component of the moral-intensity construct, defined as the degree of social agreement that a particular course of action is ethically right or wrong, is likely to facilitate the behavioral expression of individuals' idealistic values by providing normative support for behavior that is consistent with these values. Other components of moral intensity, such as magnitude of consequences, probability of effect, and temporal immediacy, may moderate the effects of individual characteristics on unethical managerial behavior by increasing the salience of the moral issue being faced and reducing the ambiguity of the consequences associated with a particular decision or course of action. This corresponds to the observations made by Lehnert et al. (2015) in that moral intensity has been linked to the fear of consequences of an action, perceived outcomes, and risks associated with actions.

Social-psychological research provides further support for the moderating role of moral intensity. Attribution biases and, in particular, the phenomenon of the actor-observer effect (Fiske and Taylor 2013) suggest that individuals may attribute their behavior to situational factors unknown to observers. Thus, rather than assuming individual characteristics to determine unethical behavior-as the observer perspective would suggest-actors tend to explain their own behavior in situational terms. Therefore, the higher the moral intensity of a situation, the more likely it will be salient for individuals, who will adjust their behavior correspondingly.

Based on this discussion, we hypothesize:

Hypothesis 1 Moral intensity moderates the relationships between individual characteristics and unethical managerial behavior, in that higher moral intensity implies a lower likelihood that individuals engage in unethical behavior.

\section{Situational Strength}

Stahl and Sully de Luque (2014), drawing on Mischel's (1968, 1973) construct of situational strength, recently proposed that psychological features in ethically charged situations may influence the behavioral expressions of personality traits in various organizational contexts, affecting individuals' "doing good" and "avoiding harm" behaviors. In line with Mischel's personality theory, they argue that the behavioral expression of managers' dispositions is likely to be suppressed by highly constraining "strong" situations, but that they might be enacted in "weak" situations. Classic experiments in social psychology, such as Milgram's (1974) work on obedience to authority and Zimbardo's (2007) prison experiment, align with this postulation and make a strong case for the importance of specific situations in determining human behavior.

According to Meyer et al. (2010, p. 137), situational strength "has long been recognized as a potentially important mechanism through which situations homogenize behaviors and influence the extent to which relevant outcomes are predictable". Relatedly, situational-strength theory has been considered and utilized by various authors (e.g., Bowen and Ostroff 2004; House and Aditya 1997) proposing that highly formalized organizations provide less opportunity for managers to exhibit their personal dispositions, and that psychologically "strong" situations tend to provide clear expectations about desired responses and behaviors. While the situational-strength concept is relatively novel in the organizational ethics field, recent studies (Ingram et al. 2007; Knoll et al. 2016; Mai et al. 2015; Noval and Stahl 2015) have started incorporating the theory both conceptually and empirically in relation to unethical behavior. For example, Knoll et al. (2016) suggest the potential use of situational strength as a moderator variable that predicts when individual differences relate to unethical behavior.

Psychologically "strong" situations are characterized by solid incentives for specific behaviors and clear behavioral norms as well as apparent expectations about what types of behaviors are rewarded or punished. Thus, in companies governed by firm role expectations and attendant policies and procedures, individuals are likely to have less room to behaviorally express their dispositional traits (Bowen and Ostroff 2004; House and Aditya 1997). These psychologically "strong" situations restrict individuals' decisionmaking capacities and scope of action as well as their abilities to influence organizational outcomes. Consequently, in such environments it is less likely that individuals who are motivated by attributes like personal gain or self-interest have the opportunity to translate such tendencies into actual unethical managerial behavior, due to the strong discouragement of such behavior embedded in the environment. Thus, we suggest that situational strength moderates the relationship between managers' individual characteristics and their unethical behavior, in that psychologically "strong" situations imply a lower likelihood that personal dispositions translate into unethical managerial behavior.

In contrast, in companies where individuals have greater discretion over their activities through being less constrained by rules, regulations, and enforcement mechanisms, they tend to have more opportunity to express their behavioral dispositions and can influence organizational outcomes. The absence of stringent company guidance and control does not inevitably result in unethical managerial 
behavior. However, such psychologically "weak" situations increase the likelihood that individuals will express their dispositions in the form of actual behavior (Stahl and Sully de Luque 2014).

Based on this discussion, we hypothesize:

Hypothesis 2 Situational strength moderates the relationships between individual characteristics and unethical managerial behavior, in that greater situational strength implies a lower likelihood that individuals engage in unethical behavior.

\section{Method}

To test these hypotheses, we used the case-survey method, which enabled us to quantify multiple real-life case studies describing unethical managerial behavior, and analyze them statistically (Bullock and Tubbs 1987; Jauch et al. 1980; Larsson 1993). The method provides an alternative to questionnaires, scenarios, and vignettes traditionally applied in organizational ethics research (Kish-Gephart et al. 2010; Lehnert et al. 2015; O'Fallon and Butterfield 2005). These approaches, frequently carried out under lab conditions, have respective limitations, such as a lack of realism or a focus on limited sets of variables. In line with the aim of this study, to examine the role of contextual moderating effects on the relationship between individual characteristics and unethical managerial behavior, the casesurvey method is therefore a valuable methodological alternative to examine the full complexities of real-life unethical managerial behavior.

Prior research has proven the usefulness of the casesurvey methodology for researching complex organizational phenomena (e.g., Larsson and Finkelstein 1999). It overcomes the lack of generalizability, which is the major disadvantage of single-case studies. By examining crosssectional patterns across cases, we can establish the generalizability of the findings, but still capture the idiographic richness of each single case. The method consists of four steps. First, we selected multiple existing case studies relevant to the research question; second, we developed a coding scheme to systematically convert the qualitative case information into quantifiable variables; third, multiple raters evaluated the cases using the coding scheme, and we measured their inter-rater reliability; fourth, we analyzed the coded data statistically.

\section{Sample}

To compile our sample, we aimed to search for and select case studies that described occurrences of real-life unethical managerial behavior. Our intention was not to assemble a representative sample of the entire population of all cases where managers engaged in unethical behavior, but one offering a good representation of the range of unethical activities in which managers may engage. For this purpose, we relied on Kaptein's (2008) taxonomy of unethical behavior, and applied the following search and selection procedure.

\section{Case-Study Search}

We performed manual and computerized searches, using a range of sources including books, Internet databases, and standard search engines. For computerized searches we used search terms like "ethical behavior", "misconduct", and "ethics". We also screened bibliographies and case catalogues for relevant case studies. These searches yielded more than 700 potentially relevant case studies. In a further step, we screened all cases in detail and selected those that met the following selection criteria.

\section{Selection Criteria}

To be included, cases needed to meet five criteria, three pertaining to the content and events described by a case, and two related to content restrictions and the quality of the actual case study. First, only cases describing real-life individual managerial behavior were eligible for inclusion. We excluded any cases that contained purely and entirely fictional elements, as is common in case studies used for educational purposes. Second, to establish the presence of unethical managerial behavior in the cases, we applied Kaptein's (2008) inductively derived and empirically tested register of unethical behavior in the view of various stakeholders. This list comprises 37 items of unethical behavior in the workplace. Cases were eligible if the unethical behavior they described corresponded to one or more items on the list. We thus ensured that cases were not selected according to subjective evaluations of the unethical behavior described, but that they matched a common frame of reference. Third, we included only case studies that described unethical managerial behavior in an organizational setting. Fourth, the case studies needed to provide adequate descriptions of the circumstances surrounding the unethical managerial behavior. Thus, case studies that centered on questions like whether or not the described behavior should be classified as ethical or unethical were excluded. Fifth, we required that the cases be written with adequate quality to permit raters to develop a consistent understanding of the events described. We provide a list of the case studies selected according to these criteria in Table 7 in the Appendix. 


\section{Sample Characteristics}

We identified 52 cases that met the selection criteria and were included in the sample. This sample size corresponds to prior case-survey studies (e.g., Larsson 1993; Larsson and Finkelstein 1999). The case studies averaged 14 pages in length, including possible appendices.

\section{Coding and Inter-rater Agreement}

We followed the guidelines provided by Larsson (1993) to code the selected cases. Each case was coded by two independent raters, including one of the authors of this study and a rater who was unaware of the hypotheses, as well as, in some cases, the authors of the case studies. To garner participation by case authors, we emailed them invitations to contribute to the coding process by rating their own case studies. For around $12 \%$ of the case studies we were able to obtain ratings from the authors.

For each variable, the coders received explanations of the underlying theoretical constructs, as part of the coding scheme. All variables were measured on five-point Likerttype scales. We determined the inter-rater agreement using the intra-class correlation coefficient (ICC). The threshold for acceptable ICCs is 0.70 , and coefficients above 0.80 indicate good reliability (Neuendorf 2002). The ICCs for the variables included in this study ranged from 0.77 to 0.97 , that is, well within the acceptable range. We provide the inter-rater reliabilities for all the study variables in Table 1 (column: ICC).

\section{Controls for Systematic Sample and Coding Bias}

Several control variables helped us ensure that the sample characteristics and research design did not imply systematic biases in terms of sampling and coding. For sampling bias, we controlled for the stakeholder affected by the observed unethical actions, the duration of the unethical managerial behavior (in years), the publisher, year of publication, and case-author participation (i.e., whether case authors participated in the coding process). We tested for the potential effects of sample characteristics and the research design using bivariate regression analysis (Larsson 1993). Of 136 correlation coefficients, 12 (9\%) were statistically significant. Most of the significant correlations were between control variables, which suggests that our case selection was not systematically biased.

Regarding coding bias, as case authors participated in the coding process, we could determine if their results differed from those of other coders because of their more in-depth knowledge about the nature and the backgrounds of the events described. According to Larsson (1993, p. 1532), "authors can be excellent third raters of their own cases" and the study may benefit from additional information as well as from the secondary validation of coding. The correlations between the author participation variable and the dependent variable were statistically not significant, in support of coding validity. In addition, in order to ensure that the coders who rated both the dependent and independent variables were not biased in their ratings, for a subset of variables-each representing one of the three antecedent sets-we provided independent raters, unfamiliar with the case studies and dependent variable, with excerpts from the case materials. From these excerpts, they were to give their ratings of single variables. Thus, we obtained codes independent of the case contexts and descriptions of unethical managerial behavior. The ICCs for the subset of variables included in this procedure ranged from 0.83 to 0.93 , which further indicated that rating bias was not a substantial issue.

\section{Measures and Properties}

\section{Unethical Managerial Behavior}

Our dependent variable was measured using a five-point Likert-type scale, asking coders about the degree of unethical behavior performed by the managers described in the case studies. The ICC for the dependent variable was 0.87. In addition, raters described the unethical managerial behavior in each case, to confirm that the cases reflected Kaptein's (2008) registry of unethical actions in business and that raters did not infer subjective associations. Kaptein's instrument contains 37 items of unethical managerial behavior in relation to financiers, customers, employees, suppliers, and society, such as "stealing or misappropriating assets", "engaging in false or deceptive sales and marketing practices", "discriminating against employees", "accepting inappropriate gifts, favors, entertainment, or kickbacks from suppliers", "providing regulators with false or misleading information". The most frequent forms of unethical behaviors identified in the cases included in this study were false or deceptive sales and marketing practices $(8 \%)$, providing regulators with misleading or false information (8\%), stealing and misappropriating assets (7\%), anti-competitive practices such as bribery or market-rigging (7\%), falsifying or manipulated financial reporting (6\%), conflicts of interest $(6 \%)$, and submission of false or misleading invoices to customers $(6 \%)$.

We determined the variables previously reviewed as antecedents of unethical managerial behavior as independent variables. Several measures for the independent variables were derived from theoretically and empirically well-established constructs, to which the coders were 
introduced, such as those for people's moral philosophies (Cohen et al. 2001; Reidenbach and Robin1990), moral intensity (Jones 1991), or ethical work climates (Simha and Cullen 2012; Victor and Cullen 1987, 1988). For constructs such as ethical work climate or moral intensity and its moral-issue characteristics, which conceptually involve various sub-dimensions, we incorporated any possible subdimensions as necessary.

\section{Individual Characteristics}

The measures for individual characteristics included the personality constructs of Machiavellianism and external locus of control, in accordance respectively with the MachIV (Christie and Geis 1970) inventory and Rotter's (1966) locus of control measure. For example, the Machiavellianism measure read: "Does the individual show Machiavellian tendencies? To what extent does the individual lean toward amoral actions, sharp dealings, hidden agendas, unethical excess or use interpersonal relationships opportunistically and deceptively?" Based on Cohen et al.'s $(1993,2001)$ redefined, validated extension of Reidenbach and Robin's (1990) Multidimensional Ethics Scale, we included five moral philosophies (MP), or ethical evaluative criteria: MP-moral equity (justice), MP-moral relativism, MP-contractualism (deontology), MP-utilitarianism, and MP-egoism. A sample coding item for MPegoism read: "Is the individual guided by the degree to which an action promotes his or her individual (long-term) goals?" The measures of the individual characteristics also included job satisfaction and ethics training attributes.

\section{Situational and Moral-Issue Characteristics}

We measured six moral-issue (MI) dimensions: MI-magnitude of consequences, MI-social consensus, MI-probability of effect, MI-temporal immediacy, MI-proximity of effect, and MI-concentration of effect (Jones 1991). For example, a coding item for MI-probability of effect asked, "How high is the probability that the action will cause the expected consequences?"

\section{Organizational Characteristics}

The measures for organizational characteristics included four ethical work climate (EWC) types that empirical research indicates to occur frequently (Bulutlar and Öz 2009; Martin and Cullen 2006; Simha and Cullen 2012; Tsai and Huang 2008): EWC-caring, EWC-law and code, EWC-rules, and EWC-instrumental. In line with KishGephart et al. (2010), we did not include EWC-independence as it tends to emphasize individuals' personal inclinations rather than organizational ethical climate. A sample coding item for EWC-caring read, "How important is the good of all people in the company?" In addition, we measured ethical culture, existence of a code of ethics, enforcement of a code of ethics, and existence of rewards and sanctions.

\section{Analyses and Results}

\section{Statistical Procedure}

We analyzed our data and tested our hypotheses with a two-step approach. In a first step, we examined the moderating effects of moral intensity and situational strength on an aggregated level, using structural equation modeling (SEM). These analyses served to test the moderating effects of moral intensity and situational strength on the relationship of the collective of all individual-characteristic antecedents included in this study and unethical managerial behavior. In a second step, we moved beyond the aggregated level to test the moderating effects of moral intensity and situational strength on the effects of single individualcharacteristic variables, using regression analysis and SEM. This second step allowed for more fine-grained insights into the specific moderating effects of moral intensity and situational strength when examined with single individual-characteristic antecedents.

The SEM analyses relied on SmartPLS version 2.0 (Ringle et al. 2005), which is useful for analyzing structural relationships among and between latent variables, as well as between latent and observed variables. For this study, SmartPLS provides two essential advantages. First, it can analyze relatively small sample sizes. ${ }^{1}$ Second, it can test for moderation effects using continuous interaction terms, as obtained from the multiplication of indicators of the underlying constructs, rather than a comparison of dichotomized groups. Because SEM suffers from the limitation of a lack of parametric significance testing, we employed SmartPLS's bootstrapping procedure, using 5000 sub-samples to obtain stable results (Hair et al. 2013a). SmartPLS yields interaction terms through the multiplication of predictor and moderator variables. As we created the interaction terms, we mean-centered the variables (Chin et al. 2003). In order to interpret the SEM

\footnotetext{
${ }^{1}$ It is generally recommended that sample size should be ten times the largest number of formative indicators used to measure one construct, or ten times the largest number of inner-model paths pointing to a particular inner-model construct (Barclay et al. 1995; Hair et al. 2014). In our case, the inner model includes three formative indicators, suggesting a minimum sample size of 30 . With 52 cases, we thus exceed the minimum sample required according to this rule of thumb.
} 
moderating effects appropriately, we followed Hair et al. (2013b) suggestions and first estimated and evaluated the main effects in the SEM path models, and in a subsequent moderator analysis included the interaction effect. For significant moderating-effect findings that ran against the logic of our hypotheses, we additionally observed the main-effect and moderation-effect scores of the variables in question and for each single case included in the statistical analyses, in order to ensure appropriate interpretations.

\section{Zero-Order Correlations}

We provide the means, standard deviations, and correlation coefficients of all variables in Table 2. The correlation matrix indicated statistically significant correlations between unethical managerial behavior and several individual and organizational antecedents, and one significant correlation with a moral-issue characteristic (MI-temporal immediacy).

\section{Aggregated-Level Analyses and Results}

Prior to testing the moderating effects of moral intensity and situational strength on an aggregated level-thus their effects on the relationships between the aggregate of all individual-characteristic antecedents included in this study and unethical managerial behavior-we first assigned all independent variables to individual, moral issue, and organizational latent variables. This model corresponds to the multiple-set framework of antecedents of unethical managerial behavior as reviewed previously. To ease interpretation, we recoded all indicator variables such that they consistently implied low levels of unethical behavior. We defined the three latent constructs-individual, moral issue, and organizational-as reflective measurement models, in that they share a common theme and their constructs exist independently of the measures used (Coltman et al. 2008). We provide the model assessment criteria for the three latent variables in Table 3.

Composite reliability scores between 0.60 and 0.70 are acceptable (Bagozzi and Yi 1988; Hair et al. 2012) and the reliabilities in our model ranged from 0.78 to 0.94 (individual 0.79 , moral issue 0.94 , organizational 0.78 ), indicating satisfactory reliabilities. To assess convergent validity, we examined the average variance extracted (AVE) values, which ranged between 0.50 and 0.80 (individual 0.50 , moral issue 0.80 , organizational 0.53 ), thus meeting the threshold criterion of 0.50 (Bagozzi and $\mathrm{Yi}$ 1988; Hair et al. 2012). To assess discriminant validity, we applied the Fornell-Larcker criterion, which requires that each latent variable's AVE must be higher than its squared correlations with any other construct (Fornell and Larcker
1981). As shown in Table 3, the AVE values for all latent constructs are higher than their squared correlations. These model assessment criteria thus suggest satisfactory validity and reliability.

The bootstrapping results carried out for this model and shown in Table 3 provide path coefficients suggesting that both individual and organizational characteristics had relatively strong and statistically significant effects on unethical managerial behavior. In contrast, the effect of the moral-issue latent variable was comparably small and statistically non-significant. The R-square value for this model was 0.89 . Collectively, these results underline the importance of individual and organizational characteristics as direct antecedents of unethical managerial behavior.

To test the two moderator hypotheses, we built models using the same individual-characteristic latent variable as in the previous model. For hypothesis 1, the moral intensity moderator variable corresponds to the moral-issue latent variable from the previous model; for hypothesis 2 , we created the situational strength latent-moderator variable by combining six organizational indicator variables: EWCcaring, EWC-law and code, EWC-rules, ethical culture, enforcement of code of ethics, and existence of rewards and sanctions (composite reliability $=0.96, \mathrm{AVE}=0.86$ ). These variables are likely to create psychologically "strong" situations as suggested by Mischel $(1968,1973)$ and discussed by Stahl and Sully de Luque (2014), in that they provide strong behavioral norms and incentives as well as clear expectations that unethical behavior is not desired. This aligns with the notion of the situationalstrength construct in that it does not emphasize the physical or actual situation per se, but rather the situation as individuals perceive it based on their cognitive maps and schemata (Bowen and Ostroff 2004). For this reason, we did not include the remaining organizational characteristics-EWC-instrumental and existence of code of ethicsas indicator variables. EWC-instrumental relates to decision-making from an egoistic and self-centered perspective, which is unlikely to provide clear expectations that unethical managerial behavior is undesirable. Regarding the existence of a code of ethics, Kish-Gephart et al. (2010) in their meta-analysis revealed that the mere existence of a code of conduct has no detectable impact on unethical choices; they instead recommended that future research should focus on how codes can be effectively enforced. In constructing the situational-strength latent variable, we therefore considered this thinking that the mere existence of a code of conduct does not contribute to creating psychologically "strong" situations.

Table 4 contains the results for the two moderation models. The R-square values of the two moderation models were 0.66 for moral intensity and 0.89 for situational strength. In both cases, the interaction terms had positive 


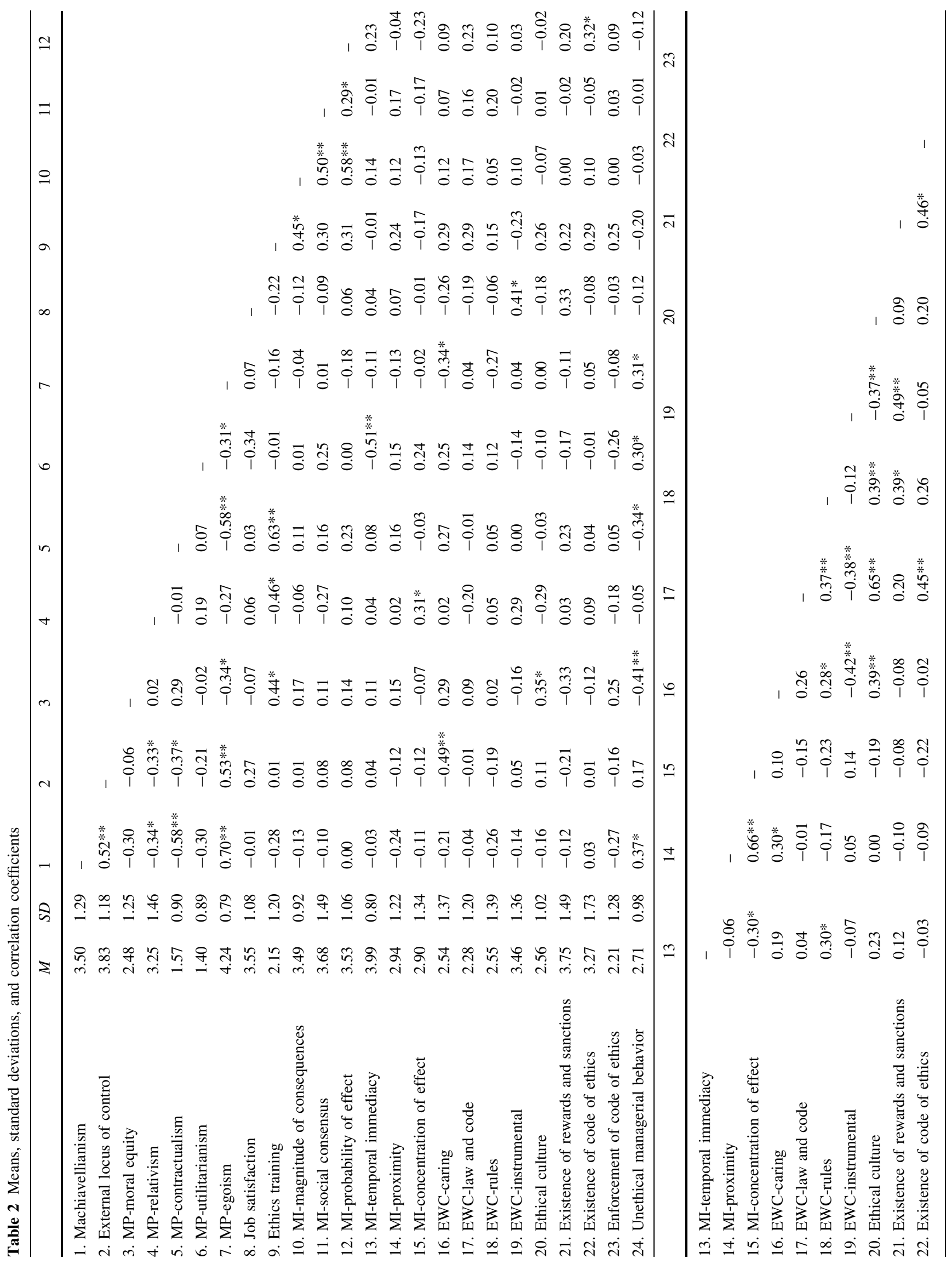




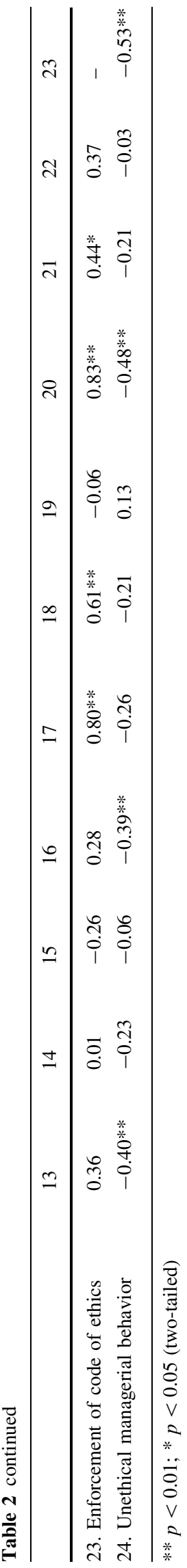

signs, such that they reinforced the relationships between individual characteristics and unethical managerial behavior. Because the effect of the individual antecedent set was negative in both cases, these analyses suggest that moral intensity and situational strength both contributed to reducing unethical managerial behavior. However, the interaction term was statistically significant only for moral intensity, in support of hypothesis 1 . In terms of effect size, this can be characterized as a large effect $\left(f^{2}=0.50\right)$ (Chin et al. 2003; Cohen 1988).

\section{Single-Variable Analyses and Results}

Before testing the moderating effects of moral intensity and situational strength on the relationships between single individual-characteristic antecedents and unethical managerial behavior, we carried out a series of regression analyses and thereby examined the relationships between each antecedent variable and the dependent variable. Results are shown in Table 5 and indicate a general pattern of variables with statistically significant effects corresponding to the analysis on the aggregated level. The effects of several individual and organizational variables were significant. Among the individual characteristics, Machiavellianism and most of the moral philosophies were notably significant. Of the organizational characteristics, EWC-caring, EWC-law and code, ethical culture, and enforcement of code of ethics were significant, with negative effects on unethical managerial behavior. Among the moral-issue characteristics, the effects of MI-temporal immediacy and MI-proximity were statistically significant, both with a negative effect on unethical managerial behavior. The signs of all significant effects were as generally indicated by the literature.

To test the moderating effects of moral intensity and situational strength on the relationships between single individual-characteristic antecedents and unethical managerial behavior, we replicated the previous aggregated SEM moderation analyses separately for each antecedent variable. Table 6 shows the moderation terms of these analyses. For moral intensity, we found statistically significant moderation terms related to Machiavellianism, MP-moral equity, MP-relativism, and MP-contractualism. We hypothesized that high moral intensity would moderate individual-characteristic effects on unethical managerial behavior, reducing unethical behavior. This logic applied to the moral philosophy variables, in support of hypothesis 1, but not to Machiavellianism. For the latter, we found that moral intensity increased the effect on unethical managerial behavior. Statistically significant interaction terms for situational strength were found for Machiavellianism, MPmoral equity, and MP-egoism. For Machiavellianism and MP-moral equity, hypothesis 2 was supported, as higher 
Table 3 Model assessment criteria and main-effects model (aggregated-effects analysis)

\begin{tabular}{llllllll}
\hline Latent variable & Composite reliability & 1 & 2 & 3 & Path coefficients & $t$ values & $R^{2}$ \\
\hline 1. Individual & 0.79 & $\mathbf{0 . 5 0}$ & & & -0.57 & $4.76^{* * *}$ & 0.89 \\
2. Moral issue & 0.94 & 0.12 & $\mathbf{0 . 8 0}$ & & -0.05 & 0.77 & \\
3. Organizational & 0.78 & 0.36 & 0.05 & $\mathbf{0 . 5 3}$ & -0.46 & $4.47^{* * *}$ & \\
\hline
\end{tabular}

Numbers on the diagonal in bold indicate the average variance extracted. Other cell values reveal the squared correlations among the latent variables. The indicator variables were recoded

$* * * p<0.01$ (two-tailed) situational strength implied lower unethical managerial behavior. In contrast, in the case of MP-egoism, higher situational strength increased the positive effect of this variable on unethical managerial behavior. In terms of effect sizes, these can be characterized as small $\left(f^{2}=0.06\right)$ to medium $\left(f^{2}=0.27\right)$ effects (Chin et al. 2003; Cohen 1988).

\section{Discussion and Implications}

While the organizational ethics literature over the last few decades has identified numerous antecedents of unethical managerial behavior, recent work points to the importance of considering situational and organizational (Kish-Gephart et al. 2010; Lehnert et al. 2015) moderating influences, given that the situation or moral issue in question as well as the organizational ethical infrastructure may considerably influence managers' unethical behavior. The complex interactions between individual characteristics and contextual moderating factors provide great potential for a more profound understanding of the boundary conditions of unethical managerial behavior. While many antecedents of unethical managerial behavior have been subject to empirical analyses as to their direct influence on such behavior, fewer studies have tested moderating effects-of which only a small number incorporated select contextual factors (Lehnert et al. 2015). One explanation for this development-besides the various conceptualizations of the determination of unethical managerial behavior throughout the last few decades - is the continued use of surveys and scenario-based studies (Craft 2013; Lehnert et al. 2015). These often lack realism and are restricted in the number of variables that can be studied, which results in natural methodological limitations with regard to testing contextual moderating influences. The case-survey method as applied in this study was useful to overcome this barrier, as it enabled us to analyze real-life occurrences of unethical behavior in its full complexity. We were thus able to adopt a holistic, multiple-antecedent perspective on
Table 4 Interaction-effects models (aggregated-effects analysis)

\begin{tabular}{|c|c|c|c|c|}
\hline Model & Path coefficients & $t$ values & $f^{2}$ & $R^{2}$ \\
\hline \multicolumn{5}{|l|}{ Moral intensity moderator } \\
\hline Individual & -0.41 & $3.28 * *$ & & \\
\hline Individual $\times$ Moral intensity & 1.52 & $2.80 * *$ & 0.50 & 0.66 \\
\hline Moral intensity & 1.11 & $1.95 *$ & & \\
\hline \multicolumn{5}{|l|}{ Situational strength moderator } \\
\hline Individual & -0.58 & $5.97 * *$ & & \\
\hline Individual $\times$ Situational strength & 0.27 & 1.49 & - & 0.89 \\
\hline Situational strength & -0.22 & $1.66^{*}$ & & \\
\hline
\end{tabular}

The indicator variables were recoded

The moral-intensity latent variable includes the following six situational and moral-issue indicator variables: MI-magnitude of consequences, MI-social consensus, MI-probability of effect, MI-temporal immediacy, MI-proximity, MI-concentration of effect

The situational-strength latent variable includes the following six organizational indicator variables: EWCcaring, EWC-law and code, EWC-rules, ethical culture, existence of rewards and sanctions, enforcement of code of ethics

$f^{2}$ effect size

$* * p<0.01 ; * p<0.10$ (two-tailed) 
Table 5 Regression analyses for single variables

\begin{tabular}{|c|c|c|c|c|c|}
\hline Variable (effect on unethical managerial behavior as indicated by the literature) & $\mathrm{B}$ & SE & Beta & $T$ statistics & $R^{2}$ \\
\hline \multicolumn{6}{|l|}{ Individual characteristics } \\
\hline Machiavellianism $(+)$ & $0.27 * *$ & 0.11 & 0.37 & 2.48 & 0.14 \\
\hline External locus of control $(+)$ & 0.14 & 0.13 & 0.17 & 1.06 & 0.03 \\
\hline MP-moral equity $(-)$ & $-0.31 * * *$ & 0.11 & -0.41 & -2.92 & 0.17 \\
\hline MP-relativism (+) & -0.03 & 0.10 & -0.05 & -0.34 & 0.00 \\
\hline MP-contractualism (-) & $-0.35^{* *}$ & 0.15 & -0.34 & -2.33 & 0.11 \\
\hline MP-utilitarianism (+) & $0.32 * *$ & 0.16 & 0.30 & 2.03 & 0.09 \\
\hline MP-egoism (+) & $0.37 * *$ & 0.17 & 0.31 & 2.09 & 0.09 \\
\hline Job satisfaction $(-)$ & -0.10 & 0.15 & -0.12 & -0.63 & 0.01 \\
\hline Ethics training $(-)$ & -0.15 & 0.14 & -0.20 & -1.08 & 0.04 \\
\hline \multicolumn{6}{|l|}{ Situational and moral-issue characteristics } \\
\hline MI-magnitude of consequences $(-)$ & -0.03 & 0.15 & -0.03 & -0.18 & 0.00 \\
\hline MI-social consensus $(-)$ & -0.01 & 0.09 & -0.01 & -0.07 & 0.00 \\
\hline MI-probability of effect $(-)$ & -0.11 & 0.13 & -0.12 & -0.85 & 0.01 \\
\hline MI-temporal immediacy (-) & $-0.49 * * *$ & 0.16 & -0.40 & -3.07 & 0.16 \\
\hline MI-proximity (-) & $-0.18^{*}$ & 0.11 & -0.23 & -1.68 & 0.05 \\
\hline MI-concentration of effect $(-)$ & -0.04 & 0.10 & -0.06 & -0.39 & 0.00 \\
\hline \multicolumn{6}{|l|}{ Organizational characteristics } \\
\hline EWC-caring (-) & $-0.26 * * *$ & 0.09 & -0.39 & -2.95 & 0.15 \\
\hline EWC-law and code $(-)$ & $-0.21^{*}$ & 0.11 & -0.26 & -1.90 & 0.06 \\
\hline EWC-rules (-) & -0.15 & 0.10 & -0.21 & -1.49 & 0.04 \\
\hline EWC-instrumental (+) & 0.09 & 0.10 & 0.13 & 0.93 & 0.02 \\
\hline Ethical culture (-) & $-0.43 * * *$ & 0.11 & -0.47 & -3.78 & 0.23 \\
\hline Existence of rewards and sanctions (-) & -0.12 & 0.10 & -0.21 & -1.20 & 0.05 \\
\hline Existence of code of ethics $(-)$ & -0.02 & 0.09 & -0.03 & -0.20 & 0.00 \\
\hline Enforcement of code of ethics (-) & $-0.34 * * *$ & 0.11 & -0.53 & -3.09 & 0.28 \\
\hline
\end{tabular}

$* * * p<0.01 ; * * p<0.05 ; * p<0.10$ (two-tailed)

unethical managerial behavior, and based on the information provided in the case studies we could model and test the moderating influences of moral intensity and situational strength.

Collectively, our analyses suggest that in addition to several individual-characteristic antecedents, situational and moral issue as well as organizational antecedents can have direct effects on unethical managerial behavior. This corresponds to how the majority of empirical organizational ethics studies tend to conceptualize the influence of these contextual factors. However, we also found support for the hypothesized contextual moderating effects, drawing on Jones's (1991) moral-intensity theory to model the immediate situation or moral issue at hand, and Mischel's (1968, 1973) situational-strength theory to model the organizational ethical infrastructure. These findings are supported by classical social-psychological research (e.g., Milgram 1974; Zimbardo 2007), and have the potential to provide important directions for future organizational ethics studies. This is particularly relevant, as there is a need to study the simultaneous moderating influences of multiple contextual variables, in contrast to their dispersed effects as antecedents - an issue which Kish-Gephart et al. (2010) identified as important for the advancement of organizational ethics research. Therefore, the constructs of moral intensity and situational strength suggest promising avenues for future studies aiming to investigate the complex contextual moderating influences on the relationship between individual characteristics and unethical behavior. Also in light of the strong emphasis of organizational ethics research on trait theory-especially the focus in empirical studies on the characteristics of individual managers (cf., O'Fallon and Butterfield 2005)—moral intensity and situational strength can be useful theoretical constructs to develop a better understanding of the boundary conditions of unethical managerial behavior and how they influence such behavior.

Our analyses of the moderating influences of moral intensity and situational strength on the relationships between single individual-characteristic variables and unethical managerial behavior suggest that these contextual factors are particularly relevant in the case of Machiavellianism and individuals' moral philosophies. Importantly, 
Table 6 Single variable interaction terms

\begin{tabular}{|c|c|c|c|}
\hline Model & Path coefficients & $t$ values & $f^{2}$ \\
\hline \multicolumn{4}{|l|}{ Moral intensity moderation effects } \\
\hline Machiavellianism $\times$ Moral intensity & 0.36 & $2.19 * *$ & 0.10 \\
\hline External locus of control $\times$ Moral intensity & 0.15 & 0.83 & - \\
\hline MP-moral equity $\times$ Moral intensity & 0.32 & $1.86^{*}$ & 0.09 \\
\hline MP-moral relativism $\times$ Moral intensity & 0.24 & $2.03 * *$ & 0.08 \\
\hline MP-contractualism $\times$ Moral intensity & 0.45 & $2.28 * *$ & 0.27 \\
\hline MP-utilitarianism $\times$ Moral intensity & 0.14 & 0.70 & - \\
\hline MP-egoism $\times$ Moral intensity & 0.10 & 0.82 & - \\
\hline Job satisfaction $\times$ Moral intensity & 0.30 & 1.37 & - \\
\hline Ethics training $\times$ Moral intensity & 0.09 & 0.35 & - \\
\hline \multicolumn{4}{|l|}{ Situational strength moderation effects } \\
\hline Machiavellianism $\times$ Situational strength & -0.50 & $2.30 * *$ & 0.06 \\
\hline External locus of control $\times$ Situational strength & 0.16 & 1.43 & - \\
\hline MP-moral equity $\times$ Situational strength & 0.38 & $1.65^{*}$ & 0.07 \\
\hline MP-moral relativism $\times$ Situational strength & 0.10 & 0.68 & - \\
\hline MP-contractualism $\times$ Situational strength & -0.11 & 1.01 & - \\
\hline MP-utilitarianism $\times$ Situational strength & -0.33 & 0.77 & - \\
\hline MP-egoism $\times$ Situational strength & 0.84 & $2.24 * *$ & 0.11 \\
\hline Job satisfaction $\times$ Situational strength & -0.25 & 1.35 & \\
\hline Ethics training $\times$ Situational strength & -0.22 & 1.51 & \\
\hline
\end{tabular}

our findings also illustrate the complex multifaceted nature of studying such contextual moderating effects, as both moral intensity and situational strength to some extent differed in how they affected the links between individual characteristics and unethical managerial behavior. At the aggregated level, both appeared equal in their directions and supported our predictions that they contribute to suppressing unethical managerial behavior, although only the moral intensity interaction term was statistically significant.

When we analyzed their interaction effects with single individual-characteristic variables and the relationships with unethical managerial behavior, several differences emerged. For example, moral intensity reinforced the positive relationship between Machiavellianism and unethical managerial behavior, whereas situational strength reduced it. The latter effect was as hypothesized, but the first is rather counter-intuitive. The ethical impulse perspective as coined by Kish-Gephart et al. (2010) may help explain this result and is in line with the increasingly discussed notion (Moore and Loewenstein 2004; Sonenshein 2007) that people may react automatically rather than deliberatively to certain ethically challenging situations. Thus, individuals facing ethically charged decisions are likely to follow a defaultprocessing route, unless they encounter novelty. As Machiavellianism indicates a willingness to manipulate (Ross and Robertson 2000) and is associated with amorality, questionable dealings, excesses, and hidden agendas
(Nelson and Gilbertson 1991), among people with Machiavellian traits moral intensity may not represent novelty but rather opportunities to mislead others for personal gain. This interpretation also suggests that there might be a need for a certain minimum degree of moral intensity - which in relative terms surpasses individuals' Machiavellianism tendencies-to have the hypothesized moderating effect. Situational strength, in contrast, may be likely to more directly provide strong behavioral norms and incentives as well as clear expectations about rewards and punishments, and therefore can suppress Machiavellian tendencies, as hypothesized. These considerations are consistent with recent neuro-scientific findings showing that individuals high in Machiavellianism might be able to make predictions about future rewards in risky, unpredictable social-dilemma situations (Bereczkei et al. 2013).

As noted above, situational strength weakened the positive relationship between Machiavellianism and unethical managerial behavior. This logic also applied to the link between MP-moral equity and unethical managerial behavior, where situational strength reinforced the negative relationship. In the case of MP-egoism, situational strength increased rather than decreased the positive effect on unethical managerial behavior. While counter-intuitive, this finding can be explained by bearing in mind recent considerations (e.g., Knoll et al. 2016; Martin et al. 2014) that strong ethical infrastructures may not always be adequate to 
avoid some forms of unethical behavior, such as those that are not clearly recognized as such. From an MP-egoism perspective, individuals may consider their behavior ethical when it promotes their long-term interests (Reidenbach and Robin 1990). Thus, if reasoned from an egoistic point of view, unethical managerial behavior may be justifiable for people, even if in the light of situational strength this behavior is not desirable. Psychological-reactance theory (Brehm 1966) provides an alternative explanation, as it suggests that when individuals are restricted in their behavioral freedom, they react to this limitation by aiming to reestablish their freedom. Consequently, as situational strength clearly restricts people's scope of action, it might trigger individuals' attempts to regain their decision freedom, particularly if they are guided by egoistic orientations. In addition, comparable considerations, as discussed above with Machiavellianism, might apply; in that a certain degree of situational strength might be required to be effective, and that individuals' reasoning based on egoistic considerations may carefully anticipate rewards and risks associated with unethical managerial behavior.

Overall, three important implications with regard to theory development derive from our study. First, rather than considering situational and moral-issue aspects as antecedents of unethical managerial behavior, their moderating influences in the form of moral intensity may provide potential for more distinct conceptualizations of how they affect unethical managerial behavior; conceptually, this implication aligns with Jones's (1991) original issue-contingent model. Second, studying the influences of the ethical infrastructure of organizations on unethical managerial behavior beyond the situational and moral-issue context requires the consideration of simultaneous effects of organizational elements. For this purpose, situational strength can provide a useful theoretical approach. Third, contingent on how contextual influences combine and affect the relationships between individual characteristics and unethical managerial behavior, different variations and patterns of combinations are likely. These may result in multiple routes by which situational and organizational contexts might affect the relationships between managers' individual characteristics and unethical behavior. Research that can grasp these multifold variations could help close the theory-practice gap that Bartlett (2003) and other authors (Lehnert et al. 2015) have identified in relation to the development of organizational ethics research. This gap relates to the opinion that individual behavior is part of a more holistic perspective that is inseparable from organizations. The key constructs of moral intensity and situational strength, for which in this study we found empirical support in terms of their contextual moderating influences, can provide solid foundations for incorporating such holistic perspectives, which align more closely with managerial reality.

\section{Limitations and Further Research}

This study suffers from two major limitations. First, the case-survey methodology, though representing a valuable alternative to the commonly applied survey and scenario approaches in organizational ethics research, restricted several variables that could have been included to those that were observable from the case materials. We could not incorporate antecedents such as CMD (Kohlberg 1969), even though past research has indicated that they represent important influences. While critics of CMD argue that different contexts can activate various behaviors and moral reasoning in response to ethical issues (Krebs and Denton 2005), which corresponds to the key findings of this study, it would be valuable to investigate such perspectives more carefully. Future research may benefit from applying case-survey oriented approaches combined with techniques that allow for detection of variables that we could not include.

Second, the criteria we applied to select suitable case studies are likely to have reduced the variance of unethical behavior observable in the case materials. While we ensured that our case-study sample is a good representation of the range of unethical activities in which managers may engage, our findings may not be generalizable to different types of behaviors (e.g., ethical behaviors, pro-social behaviors, responsible behaviors). Therefore, additional research could further test the contextual moderating influences of moral intensity and situational strength in relation to these behaviors. Such research could also be extended to other components of the ethical decision-making process, such as intentions, in order to determine at which stage and in which configurations contextual moderating influences of the situation and moral issue at hand as well as of the organizational setting come into play. Furthermore, with regard to generalizability our findings need to be interpreted carefully considering the relatively small sample size. Our sample meets the general rules of thumb (e.g., Hair et al. 2014) of minimum sample size required for the SEM procedures applied in this study. However, in addition to extending to other types of variables as mentioned above, future research might benefit from testing on larger samples the moderating roles of moral intensity and situational strength.

Acknowledgements Open access funding provided by Vienna University of Economics and Business (WU).

Open Access This article is distributed under the terms of the Creative Commons Attribution 4.0 International License (http://crea tivecommons.org/licenses/by/4.0/), which permits unrestricted use, distribution, and reproduction in any medium, provided you give appropriate credit to the original author(s) and the source, provide a link to the Creative Commons license, and indicate if changes were made. 


\section{Appendix}

See Table 7.

Table 7 Included case studies

\begin{tabular}{|c|c|c|c|}
\hline Case title & $\begin{array}{l}\text { Published/ } \\
\text { version }\end{array}$ & Publisher & $\begin{array}{l}\text { Unethical behavior } \\
\text { toward* }\end{array}$ \\
\hline 1. BOEING'S UNETHICAL PRACTICES & 2004 & IBS & $\mathrm{F}, \mathrm{C}$ \\
\hline $\begin{array}{l}\text { 2. DOING THE RIGHT THING: BANK ONE'S RESPONSE TO THE } \\
\text { MUTUAL FUND SCANDAL }\end{array}$ & 2004 & Thunderbird & $\mathrm{F}, \mathrm{C}$ \\
\hline 3. THE BRIBERY SCANDAL AT SIEMENS AG & 2010 & IBS & $\mathrm{C}$ \\
\hline $\begin{array}{l}\text { 4. THE HOLLINGER MEDIA GROUP LORD BLACK: FALL OF A } \\
\text { MEDIA TYCOON }\end{array}$ & 2005 & IESE & $\mathrm{F}$ \\
\hline 5. THE JULIE ROEHM SAGA AT WAL-MART STORES, INC & 2008 & IBS & $\mathrm{E}, \mathrm{Su}$ \\
\hline 6. CITIGROUP'S SHAREHOLDER TANGO IN BRAZIL & 2007 & Kellogg & $\mathrm{F}$ \\
\hline 7. PUTNAM INVESTMENTS: REBUILDING THE CULTURE & 2006 & Harvard & $\mathrm{F}$ \\
\hline 8. BOEING'S DEFENSE DEALS AND ETHICAL ISSUES & 2004 & IBS & F, C, So \\
\hline $\begin{array}{l}\text { 9. KPMG FORENSIC: MONEY LAUNDERING AT AGNES } \\
\text { INSURANCE }\end{array}$ & 2004 & Ivey & F, So \\
\hline 10. ROSSIN GREENBERG SERONICK \& HILL INC & 1993 & Harvard & $\mathrm{C}$ \\
\hline 11. MANVILLE CORPORATION FIBER GLASS GROUP & 2009 & Harvard & C, E, So \\
\hline $\begin{array}{l}\text { 12. SOUTHWESTERN OHIO STEEL COMPANY, LP: THE } \\
\text { MATWORKS DECISION }\end{array}$ & 1999 & $\begin{array}{l}\text { NACRA/The Case Research } \\
\text { Journal }\end{array}$ & $\mathrm{C}$ \\
\hline 13. INTERNATIONAL DRILLING CORPORATION & 1983 & Harvard & F, So \\
\hline 14. NICK ZANE & 1999 & Harvard & $\mathrm{F}, \mathrm{E}$ \\
\hline 15. MARY SIMMONS & 2010 & Stanford & $\mathrm{C}$ \\
\hline 16. A LETTER FROM PRISON & 2009 & Harvard & F, So \\
\hline $\begin{array}{l}\text { 17. CONTRACT MANUFACTURING: DEALING WITH SUPPLY } \\
\text { CHAIN ETHICS CHALLENGES }\end{array}$ & 2008 & Stanford & $\mathrm{Su}$ \\
\hline 18. DIFFERENCES AT WORK: SAMEER & 2008 & Harvard & $\mathrm{E}$ \\
\hline 19. DIFFERENCES AT WORK: MARTIN & 2009 & Harvard & $\mathrm{E}$ \\
\hline 20. DOW CHEMICAL AND AGENT ORANGE IN VIETNAM & 2008 & Emerald/The CASE Journal & So \\
\hline $\begin{array}{l}\text { 21. HYDROFRUIT, INC: RIPE FOR HARVEST OR ROTTEN } \\
\text { TOMATO? }\end{array}$ & 2010 & Darden & So \\
\hline 22. LEADING CITIGROUP & 2008 & Harvard & $\mathrm{C}$ \\
\hline 23. NORWAY SELLS WAL-MART & 2009 & Harvard & E, So \\
\hline 24. AN ETHICAL ISSUE AT GENERAL ELECTRIC & 2006 & Tecnológico de Monterrey & $\mathrm{F}$ \\
\hline 25. ETHICAL DILEMMA: ALBERTO MONTES & 2006 & IMD & $\mathrm{C}$ \\
\hline 26. THE AHOLD CRISIS & 2006 & Nyenrode & $\mathrm{F}$ \\
\hline 27. ETHICAL DILEMMA: GAVARE-YAMAMOTO CORP & 2006 & IMD & $\mathrm{C}$ \\
\hline 28. LIVEDOOR: THE RISE AND FALL OF A MARKET MAVERICK & 2006 & Asia Case Research Centre & F, So \\
\hline 29. COKE IN KERALA & 2005 & CIBER & C, So \\
\hline $\begin{array}{l}\text { 30. ZENECA'S DIRECT-TO-CONSUMER ADVERTISING OF } \\
\text { NOLVADEX (R) }\end{array}$ & 2005 & Stanford & C, So \\
\hline 31. IMPLA PHARMACEUTICALS LTD & 2004 & $\begin{array}{l}\text { Prestige Institute of } \\
\text { Management \& Research }\end{array}$ & $\mathrm{E}$ \\
\hline 32. CONSTANTIA INSURANCE: NO SECOND CHANCES & 2003 & Wits Business School & $\mathrm{F}$ \\
\hline 33. REIN CHEMICAL COMPANY: SPECIALTY DIVISION & 2005 & Harvard & $\mathrm{C}$ \\
\hline 34. SEARS AUTO CENTERS & 2004 & Harvard & $\mathrm{C}$ \\
\hline 35. THE DELTA ELECTRONICS CORPORATION & 2003 & $\begin{array}{l}\text { NACRA/The Case Research } \\
\text { Journal }\end{array}$ & So \\
\hline
\end{tabular}


Table 7 continued

\begin{tabular}{|c|c|c|c|}
\hline Case title & $\begin{array}{l}\text { Published/ } \\
\text { version }\end{array}$ & Publisher & $\begin{array}{l}\text { Unethical behavior } \\
\text { toward* }\end{array}$ \\
\hline 36. ORANGEWERKS: A QUESTION OF ETHICS & 2001 & Ivey & F, E, So \\
\hline 37. COLUMBIA/HCA AND THE MEDICARE FRAUD SCANDAL & 2000 & $\begin{array}{l}\text { NACRA/The Case Research } \\
\text { Journal }\end{array}$ & F, C, So \\
\hline 38. DILEMMA AT DEVIL'S DEN & 2004 & Babson College & $\mathrm{F}$ \\
\hline 39. TIM HERTACH AT GL CONSULTING & 2002 & Harvard & $\mathrm{C}$ \\
\hline 40. COMMUNITY AIDS NETWORK, INC (CAN) & 1998 & $\begin{array}{l}\text { NACRA/The Case Research } \\
\text { Journal }\end{array}$ & F, So \\
\hline 41. FRANCO BERNABE AT ENI & 2002 & Harvard & $\mathrm{F}, \mathrm{C}$ \\
\hline $\begin{array}{l}\text { 42. DATA GENERAL AND NEW YORK'S DIVISION OF } \\
\text { SUBSTANCE ABUSE SERVICES }\end{array}$ & 1994 & $\begin{array}{l}\text { NACRA/The Case Research } \\
\text { Journal }\end{array}$ & $\mathrm{C}$ \\
\hline 43. LEADERSHIP PROBLEMS AT SALOMON & 1994 & Harvard & So \\
\hline 44. A BRUSH WITH AIDS & 1994 & Harvard & C, So \\
\hline 45. BAYBANK BOSTON & 1997 & Harvard & $\mathrm{C}$ \\
\hline 46. CONFLICT ON A TRADING FLOOR & 2006 & Harvard & $\mathrm{C}$ \\
\hline 47. WESTCHESTER DISTRIBUTING, INC & 2010 & Harvard & C, So \\
\hline 48. GENERAL ELECTRIC: VALLEY FORGE & 1991 & Harvard & $\mathrm{C}$ \\
\hline 49. TONY SANTINO & 1981 & Harvard & $\mathrm{C}$ \\
\hline 50. THE FALL OF ENRON & 2010 & Harvard & $\mathrm{F}$ \\
\hline 51. ACCOUNTING FRAUD AT WORLDCOM & 2007 & Harvard & F, E, So \\
\hline 52. THE 'BERNARD MADOFF' FINANCIAL SCAM & 2009 & IBS & $\mathrm{F}$ \\
\hline
\end{tabular}

$F$ Financiers, $C$ Customers, $E$ Employees, $S u$ Suppliers, So Society

* According to Kaptein's (2008) classification in relation to stakeholder groups

\section{References}

Adams, J. S. (1965). Inequity in social exchange. In L. Berkowitz (Ed.), Advances in experimental social psychology (Vol. 2, pp. 267-299). New York: Academic Press.

Bagozzi, R. P., \& Yi, Y. (1988). On the evaluation of structural equation models. Journal of the Academy of Marketing Science, 16(1), 74-94.

Barclay, D., Higgins, C., \& Thompson, R. (1995). The partial least squares (PLS) approach to causal modeling: Personal computer adoption and use as an illustration. Technology Studies, 2(2), 285-309.

Bartlett, D. (2003). Management and business ethics: A critique and integration of ethical decision-making models. British Journal of Management, 14(3), 223-235.

Bereczkei, T., Deak, A., Papp, P., Perlaki, G., \& Orsi, G. (2013). Neural correlates of Machiavellian strategies in a social dilemma task. Brain and Cognition, 82(1), 108-116.

Bowen, D. E., \& Ostroff, C. (2004). Understanding HRM-firm performance linkages: The role of the "strength" of the HRM system. Academy of Management Review, 29(2), 203-221.

Brehm, J. W. (1966). A theory of psychological reactance. New York: Academic Press.

Brief, A. P., Dukerich, J. M., Brown, P. R., \& Brett, J. F. (1996). What's wrong with the Treadway Commission Report? Experimental analyses of the effects of personal values and codes of conduct on fraudulent financial reporting. Journal of Business Ethics, 15(2), 183-198.

Bullock, R. J., \& Tubbs, M. E. (1987). The case meta-analysis method for OD. In R. W. Woodman \& W. A. Pasmore (Eds.), Research in organizational change and development (Vol. 1, pp. 171-228). Greenwich, CT: JAI Press.

Bulutlar, F., \& Öz, E. U. (2009). The effects of ethical climates on bullying behaviour in the workplace. Journal of Business Ethics, 86(3), 273-295.

Chin, W. W., Marcolin, B. L., \& Newsted, P. R. (2003). A partial least squares latent variable modeling approach for measuring interaction effects: Results from a Monte Carlo simulation study and an electronic-mail emotion/adoption study. Information Systems Research, 14(2), 189-217.

Christie, R., \& Geis, F. L. (1970). Studies in Machiavellianism. New York: Academic Press.

Cleek, M. A., \& Leonard, S. L. (1998). Can corporate codes of ethics influence behavior? Journal of Business Ethics, 17(6), 619-630.

Cohen, J. (1988). Statistical power analysis for the behavioral sciences. Hillsdale, NJ: Lawrence Erlbaum Associates.

Cohen, J. R., Pant, L. W., \& Sharp, D. J. (1993). A validation and extension of a multidimensional ethics scale. Journal of Business Ethics, 12(1), 13-26.

Cohen, J. R., Pant, L. W., \& Sharp, D. J. (2001). An examination of differences in ethical decision-making between Canadian business students and accounting professionals. Journal of Business Ethics, 30(4), 319-336.

Coltman, T., Devinney, T. M., Midgley, D. F., \& Venaik, S. (2008). Formative versus reflective measurement models: Two applications of formative measurement. Journal of Business Research, 61(12), 1250-1262.

Craft, J. L. (2013). A review of the empirical ethical decision-making literature: 2004-2011. Journal of Business Ethics, 117(2), 221-259. 
Fiske, S. T., \& Taylor, S. E. (2013). Social cognition: From brains to culture (2nd ed.). Thousand Oaks, CA: Sage.

Flannery, B. L., \& May, D. R. (2000). Environmental ethical decision making in the U.S. metal-finishing industry. The Academy of Management Journal, 43(4), 642-662.

Fornell, C., \& Larcker, D. F. (1981). Evaluating structural equation models with unobservable variables and measurement error. Journal of Marketing Research, 18(1), 39-50.

Fritzsche, D. J. (1991). A model of decision-making incorporating ethical values. Journal of Business Ethics, 10(11), 841-852.

Gilbert, F. (1971). Machiavelli. In R. Schwoebel (Ed.), Renaissance men and ideas. New York: St. Martin's Press.

Hair, J. F., Hult, G. T. M., Ringle, C. M., \& Sarstedt, M. (2013a). A primer on partial least squares structural equation modeling (PLS-SEM). Thousand Oaks, CA: Sage.

Hair, J. F., Ringle, C. M., \& Sarstedt, M. (2013b). Partial least squares structural equation modeling: Rigorous applications, better results and higher acceptance. Long Range Planning, 46(1-2), $1-12$.

Hair, J. F., Sarstedt, M., Hopkins, L., \& Kuppelwieser, V. G. (2014). Partial least squares structural equation modeling (PLS-SEM): An emerging tool in business research. European Business Review, 26(2), 106-121.

Hair, J. F., Sarstedt, M., Ringle, C. M., \& Mena, J. A. (2012). An assessment of the use of partial least squares structural equation modeling in marketing research. Journal of the Academy of Marketing Science, 40(3), 414-433.

House, R. J., \& Aditya, R. N. (1997). The social scientific study of leadership: Quo vadis? Journal of Management, 23(3), 409-473.

Hunt, S. D., \& Vitell, S. J. (1986). A general theory of marketing ethics. Journal of Macromarketing, 6(1), 5-16.

Hunt, S. D., \& Vitell, S. J. (1993). The general theory of marketing ethics: A retrospective and revision. In N. C. Smith \& J. A. Quelch (Eds.), Ethics in marketing (pp. 775-784). Homewood, IL: Richard D. Irwin Inc.

Hunt, S. D., \& Vitell, S. J. (2006). The general theory of marketing ethics: A revision and three questions. Journal of Macromarketing, 26(2), 143-153.

Ingram, T., LaForge, R., \& Schwepker, C. (2007). Salesperson ethical decision making: The impact of sales leadership and sales management control strategy. Journal of Personal Selling and Sales Management, 27(4), 301-315.

Jauch, L. R., Osborn, R. N., \& Martin, T. N. (1980). Structured content analysis of cases: A complementary method for organizational research. Academy of Management Review, 5(4), $517-525$.

Jones, T. M. (1991). Ethical decision making by individuals in organizations: An issue-contingent model. Academy of Management Review, 16(2), 366-395.

Kaptein, M. (2008). Developing a measure of unethical behavior in the workplace: A stakeholder perspective. Journal of Management, 34(5), 978-1008.

Kish-Gephart, J. J., Harrison, D. A., \& Treviño, L. K. (2010). Bad apples, bad cases, and bad barrels: Meta-analytic evidence about sources of unethical decisions at work. Journal of Applied Psychology, 95(1), 1-31.

Knoll, M., Lord, R. G., Petersen, L.-E., \& Weigelt, O. (2016). Examining the moral grey zone: The role of moral disengagement, authenticity, and situational strength in predicting unethical managerial behavior. Journal of Applied Social Psychology, 46(1), 65-78.

Kohlberg, L. (1969). Stage and sequence: The cognitive-developmental approach to socialization. In D. A. Goslin (Ed.), Handbook of socialization theory and research (pp. 347-380). Chicago: Rand McNally.
Krebs, D. L., \& Denton, K. (2005). Toward a more pragmatic approach to morality: A critical evaluation of Kohlberg's model. Psychological Review, 112(3), 629-649.

Larsson, R. (1993). Case survey methodology: Quantitative analysis of patterns across case studies. Academy of Management Journal, 36(3), 1515-1546.

Larsson, R., \& Finkelstein, S. (1999). Integrating strategic, organizational, and human resource perspectives on mergers and acquisitions: A case survey of synergy realization. Organization Science, 10(1), 1-26.

Laufer, W. S. (1999). Corporate liability, risk shifting, and the paradox of compliance. Vanderbilt Law Review, 52(5), $1343-1420$.

Lehnert, K., Park, Y. H., \& Singh, N. (2015). Research note and review of the empirical ethical decision-making literature: Boundary conditions and extensions. Journal of Business Ethics, 129(1), 195-219.

Leitsch, D. L. (2004). Differences in the perceptions of moral intensity in the moral decision process: An empirical examination of accounting students. Journal of Business Ethics, 53(3), 313-323.

Mai, K. M., Ellis, A. P. J., \& Welsh, D. T. (2015). The gray side of creativity: Exploring the role of activation in the link between creative personality and unethical behavior. Journal of Experimental Social Psychology, 60, 76-85.

Martin, K. D., \& Cullen, J. B. (2006). Continuities and extensions of ethical climate theory: A meta-analytic review. Journal of Business Ethics, 69(2), 175-194.

Martin, S. R., Kish-Gephart, J. J., \& Detert, J. R. (2014). Blind forces: Ethical infrastructures and moral disengagement in organizations. Organizational Psychology Review, 4(4), 295-325.

May, D. R., \& Pauli, K. P. (2002). The role of moral intensity in ethical decision making: A review and investigation of moral recognition, evaluation, and intention. Business and Society, 41(1), 84-117.

McCabe, D. L., Treviño, L. K., \& Butterfield, K. D. (1996). The influence of collegiate and corporate codes of conduct on ethicsrelated behavior in the workplace. Business Ethics Quarterly, 6(4), 461-476.

Meyer, R. D., Dalal, R. S., \& Hermida, R. (2010). A review and synthesis of situational strength in the organizational sciences. Journal of Management, 36(1), 121-140.

Milgram, S. (1974). Obedience to authority. New York: Harper \& Row.

Mischel, W. (1968). Personality and assessment. New York: Wiley.

Mischel, W. (1973). Toward a cognitive social learning reconceptualization of personality. Psychological Review, 80(4), 252-283.

Moore, C., \& Gino, F. (2015). Approach, ability, aftermath: A psychological process framework of unethical behavior at work. The Academy of Management Annals, 9(1), 235-289.

Moore, D. A., \& Loewenstein, G. (2004). Self-interest, automaticity, and the psychology of conflict of interest. Social Justice Research, 17(2), 189-202.

Nelson, G., \& Gilbertson, D. (1991). Machiavellianism revisited. Journal of Business Ethics, 10(8), 633-639.

Neuendorf, K. A. (2002). The content analysis guidebook. Thousand Oaks, CA: Sage.

Noval, L. J., \& Stahl, G. K. (2015). Accounting for proscriptive and prescriptive morality in the workplace: The double-edged sword effect of mood on managerial ethical decision making. Journal of Business Ethics. doi:10.1007/s10551-015-2767-1.

O'Fallon, M. J., \& Butterfield, K. D. (2005). A review of the empirical ethical decision-making literature: 1996-2003. Journal of Business Ethics, 59(4), 375-413.

Palmer, D. (2013). The new perspective on organizational wrongdoing. California Management Review, 56(1), 5-23. 
Reidenbach, R. E., \& Robin, D. P. (1990). Toward the development of a multidimensional scale for improving evaluations of Business Ethics. Journal of Business Ethics, 9(8), 639-653.

Rest, J. (1986). Moral development: advances in research and theory. New York: Praeger.

Richards, C. (1999). The transient effects of limited ethics training. Journal of Education for Business, 74(6), 332-334.

Ringle, C. M., Wende, S., \& Will, A. (2005). SmartPLS. Hamburg. Retrieved from http://www.smartpls.de.

Ross, W. T., \& Robertson, D. C. (2000). Lying: The impact of decision context. Business Ethics Quarterly, 10(2), 409-440.

Rotter, J. B. (1966). Generalized expectancies for internal versus external control of reinforcement. Psychological Monographs, $80(1), 1-28$.

Schneider, B. (1983). Work climates: An interactionist perspective. In N. W. Feimer \& E. S. Geller (Eds.), Environmental psychology: Directions and perspectives (pp. 106-128). New York: Praeger.

Simha, A., \& Cullen, J. (2012). Ethical climates and their effects on organizational outcomes - implications from the past, and prophecies for the future. The Academy of Management Perspectives, 26(4), 20-34.

Sonenshein, S. (2007). The role of construction, intuition, and justification in responding to ethical issues at work: The sensemaking-intuition model. The Academy of Management Review, 32(4), 1022-1040.

Stahl, G. K., \& Sully de Luque, M. (2014). Antecedents of responsible leader behavior: A research synthesis, conceptual framework, and agenda for future research. The Academy of Management Perspectives, 28(3), 235-254.

Stansbury, J., \& Barry, B. (2007). Ethics programs and the paradox of control. Business Ethics Quarterly, 17(2), 239-261.

Treviño, L. K. (1986). Ethical decision making in organizations: A person-situation interactionist model. Academy of Management Review, 11(3), 601-617.

Treviño, L. K. (1992). The social effects of punishment in organizations: A justice perspective. Academy of Management Review, 17(4), 647-676.
Treviño, L. K., Butterfield, K. D., \& McCabe, D. L. (1998). The ethical context in organizations: Influences on employee attitudes and behaviors. Business Ethics Quarterly, 8(3), 447-476.

Treviño, L. K., den Nieuwenboer, N. A., \& Kish-Gephart, J. J. (2014). (Un)ethical behavior in organizations. Annual Review of Psychology, 65, 635-660.

Treviño, L. K., \& Weaver, G. R. (2003). Managing ethics in business organizations: social scientific perspective. Stanford, CA: Stanford University Press.

Treviño, L. K., \& Youngblood, S. A. (1990). Bad apples in bad barrels: A causal analysis of ethical decision-making behavior. Journal of Applied Psychology, 75(4), 378-385.

Tsai, M. T., \& Huang, C. C. (2008). The relationship among ethical climate types, facets of job satisfaction, and the three components of organizational commitment: A study of nurses in Taiwan. Journal of Business Ethics, 80(3), 565-581.

Valentine, S. R., \& Bateman, C. R. (2011). The impact of ethical ideologies, moral intensity, and social context on sales-based ethical reasoning. Journal of Business Ethics, 102(1), 155-168.

Victor, B., \& Cullen, J. B. (1987). A theory and measure of ethical climate in organizations. In W. C. Frederick (Ed.), Empirical studies of business ethics and values (pp. 51-71). Greenwich, CT: JAI Press.

Victor, B., \& Cullen, J. B. (1988). The organizational bases of ethical work climates. Administrative Science Quarterly, 33(1), 101-125.

Warren, D. E., Gaspar, J. P., \& Laufer, W. S. (2014). Is formal ethics training merely cosmetic? A study of ethics training and ethical organizational culture. Business Ethics Quarterly, 24(1), 85-117.

Wilson, D. S., Near, D., \& Miller, R. R. (1996). Machiavellianism: A synthesis of the evolutionary and psychological literatures. Psychological Bulletin, 119(2), 285-299.

Wimbush, J. C., Shepard, J. M., \& Markham, S. E. (1997). An empirical examination of the multi-dimensionality of ethical climate in organizations. Journal of Business Ethics, 16(1), 67-77.

Zimbardo, P. (2007). The lucifer effect: How good people turn evil. London: Rider. 